\title{
Quantum dot therapeutics: a new class of radical therapies
}

\author{
Max Levy ${ }^{1,2}$, Partha P. Chowdhury ${ }^{1,2}$ and Prashant Nagpal 1,2,3*
}

\begin{abstract}
Traditional therapeutics and vaccines represent the bedrock of modern medicine, where isolated biochemical molecules or designed proteins have led to success in treating and preventing diseases. However, several adaptive pathogens, such as multidrug-resistant (MDR) superbugs, and rapidly evolving diseases, such as cancer, can evade such molecules very effectively. This poses an important problem since the rapid emergence of multidrugresistance among microbes is one of the most pressing public health crises of our time-one that could claim more than 10 million lives and 100 trillion dollars annually by 2050. Several non-traditional antibiotics are now being developed that can survive in the face of adaptive drug resistance. One such versatile strategy is redox perturbation using quantum dot (QD) therapeutics. While redox molecules are nominally used by cells for intracellular signaling and other functions, specific generation of such species exogenously, using an electromagnetic stimulus (light, sound, magnetic field), can specifically kill the cells most vulnerable to such species. For example, recently QD therapeutics have shown tremendous promise by specifically generating superoxide intracellularly (using light as a trigger) to selectively eliminate a wide range of MDR pathogens. While the efficacy of such QD therapeutics was shown using in vitro studies, several apparent contradictions exist regarding QD safety and potential for clinical applications. In this review, we outline the design rules for creating specific QD therapies for redox perturbation; summarize the parameters for choosing appropriate materials, size, and capping ligands to ensure their facile clearance; and highlight a potential path forward towards developing this new class of radical QD therapeutics.
\end{abstract}

Keywords: Radical antimicrobials, Multidrug-resistant superbugs, Quantum dot therapeutic, Reactive oxygen species

\section{Introduction}

Reduction and oxidation reactions form the core of most significant processes in biology, where the majority of biological interactions, signaling, and basic cellular biology involves either a gain or loss of electrons or ionic species/ radicals [1]. Most prominently, many redox species are regulatory and believed to be used for molecular signaling and as activators of stress response [2-6]. Others, however, can cause indiscriminate oxidative damage and dysfunction [7-12]. Chemical reactions such as Fenton chemistry [13], enzymatic conversions, and disproportionation [14], can convert these species into others-such as the conversion of superoxide into hydrogen peroxide,

\footnotetext{
*Correspondence: pnagpal@colorado.edu

${ }^{1}$ Chemical and Biological Engineering, University of Colorado Boulder, Boulder, CO 80303, USA

${ }^{2}$ Renewable and Sustainable Energy Institute, University of Colorado Boulder, Boulder, CO 80303, USA

Full list of author information is available at the end of the article
}

hydroxyl radicals, and peroxynitrite ions $[13,15,16]$. Therefore, careful choice of desired biological targets, mechanistic insights into redox species and their outcome inside a cell, and precise control over their intracellular generation can provide a vital tool for precision or specific killing of cellular species vulnerable to a chosen redox perturbation, that can be triggered by stimuli to act as a therapeutic.

\section{Designing for a "radical" approach}

While many traditional antibiotics have suffered failure against adaptive resistance, a versatile approach to address this dynamic problem is emerging. Where traditional small-molecule antimicrobials struggled with transport into gram-negative pathogen cell walls, nanoparticle-based therapeutics have shown remarkable stability, ease of delivery, and facile transport through cell walls due to their small size [17-21]. Once inside 
the cell, the nanoparticle or QD therapy can make use of the presence of oxygen, water, and if required, an external trigger. Therefore a wide range of reactive oxygen species (ROS, e.g. superoxide $\mathrm{O}_{2}{ }^{\bullet-}$, hydroxyl $\mathrm{OH}^{\bullet}$, singlet oxygen ${ }^{1} \mathrm{O}_{2}$, and hydrogen peroxide $\mathrm{H}_{2} \mathrm{O}_{2}$ ) and reactive nitrogen species (RNS, e.g. nitric oxide $\mathrm{NO}^{\bullet}$, peroxynitrite $\mathrm{ONOO}^{-}$) can be formed intracellularly using redox chemistry. Since these species are responsible for a broad range of physiology and pathology in living organisms [22, 23], they have been investigated for such potential applications as cancer therapies and novel antimicrobials. Therefore, specific intracellular generation of these species can drastically affect the specificity of ROS/RNS therapy using the proposed redox perturbation.

Recently, our group assessed these different ROS and RNS species as potential therapeutics [24]. Using these species intracellularly, we determined their respective minimum inhibitory concentration (MIC) values. We found a bactericidal effect for several species at high threshold concentrations (singlet oxygen: $1 \mathrm{mM}$; peroxide: $10 \mathrm{mM}$; hydroxyl radical $>10 \mathrm{mM}$; nitric oxide $>1 \mathrm{mM}$, Fig. 1) [24, 25], where these redox species would be toxic even for host mammalian cells [26-28]. However, superoxide was found to be a potent bactericidal at low nanomolar doses-killing a range of multidrug-resistant (MDR) pathogens without affecting the viability or growth of host mammalian cells in in vitro measurements $[19,20$, 24, 29]. This difference in nanotherapeutic toxicity between host and the targeted pathogen is important for designing the safest possible treatment. Biological specificity enables a treatment to effectively clear infections while preserving the host cells. Although the superoxide anion has a high thermodynamic capacity to be a strong oxidant, its lack of reactivity with cellular components at physiological $\mathrm{pH}$ (largely due to electrostatic repulsion with negatively charged biomolecules)--except for the inactivation of biosynthetic enzymes containing labile iron-sulfur clusters--is key to its selectivity $[25,30]$. Further, the role of iron sequestration in host colonization makes pathogenic bacteria particularly vulnerable to superoxide compared to hosts [31, 32]. Therefore, while several ROS species like hydroxyl radicals are indiscriminate oxidants and can readily oxidize proteins, lipids, and nucleic acids [8,33], prior studies and our experiments indicate specificity in the of superoxide anions [19, $20,24,29,34,35]$. Given the specificity of

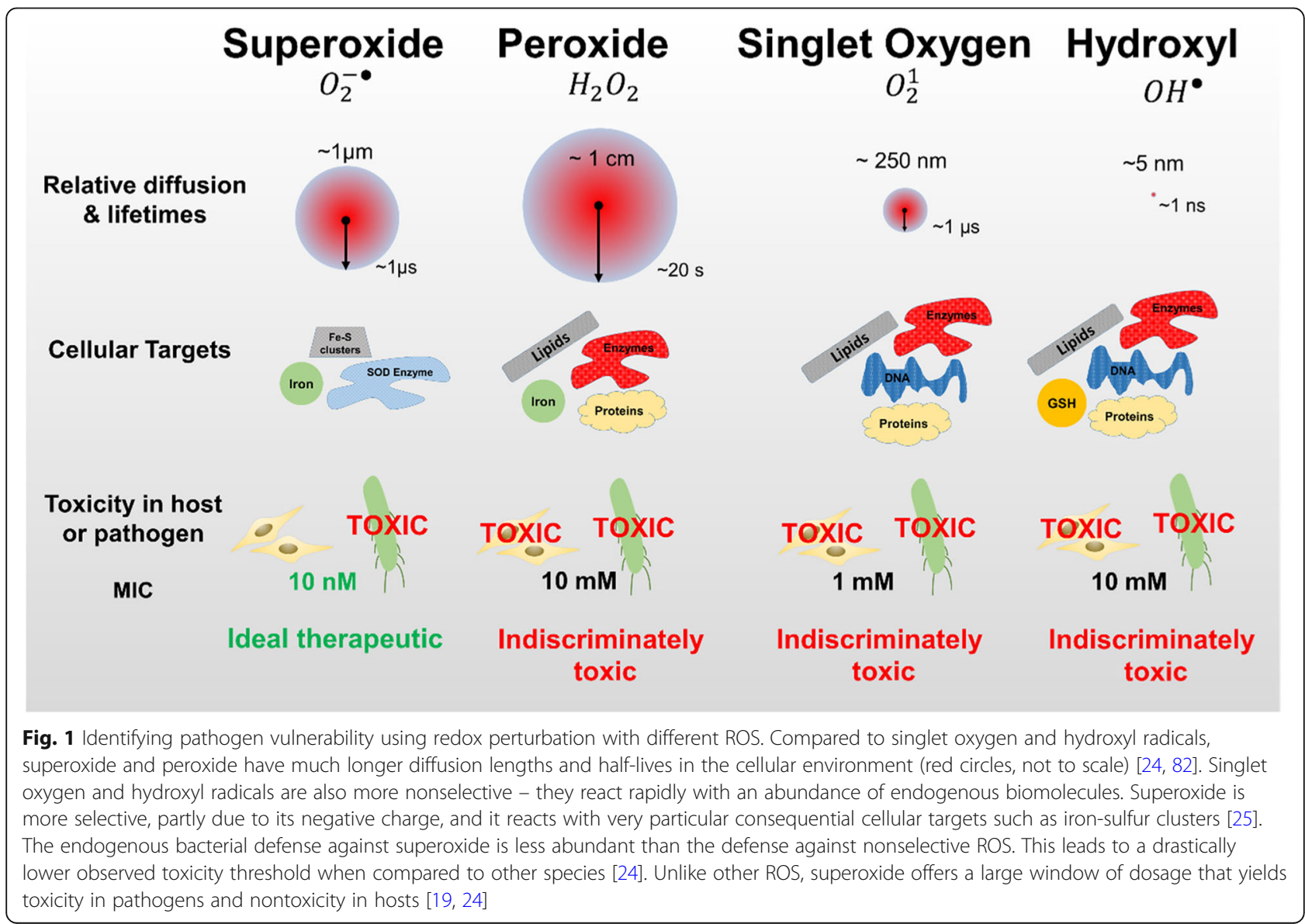


superoxide's mechanism of action, the low MIC value for pathogens and higher tolerance in host mammalian cells, its long lifetime and large diffusion length make it an ideal candidate for selective redox therapy.

\section{Selective redox activation using quantum states}

QDs, or semiconductor nanocrystals, have size-, shape-, and composition-tunable quantum states for reduction and oxidation reactions. These states can be triggered by external electromagnetic radiation like light, and have demonstrated a promising role in non-traditional redox therapy $[17-20,24,29]$. Precise control over their photogenerated electron and hole states provides a unique ability to tailor their photochemistry in the cellular environment, thereby providing control over intracellular redox species. As the first step towards designing an effective QD therapeutic, we assessed a range of different materials, along with their corresponding (bulk) reduction and oxidation states (Fig. 2a). To select for specific intracellular generation of superoxide, the reduction potential should exceed $-0.33 \mathrm{~V}$ on normal hydrogen electrode (NHE) scale. Simultaneously, to avoid the formation of other non-specific ROS species that can cause indiscriminate cell damage, the oxidation potential should be less than $1.8 \mathrm{~V} \mathrm{NHE}$. Using this metric as a selection criterion for selective redox antimicrobial therapy, and classifying the materials on the basis of their nominal (bulk) bandgap values, we obtained a list of 'favorable' materials for the proposed QD nanotherapy. Keeping in mind the extinction of light as it enters the skin considering the most common constituents as water, hemoglobin, melanin, etc. [20,36, 37], there is a window of nominal biological transparency $(\sim 800-1300$ $\mathrm{nm}$ wavelength), which narrows the material and bandgap considerations further (Fig. 2b-d). Materials which absorb violet and UV light are less suitable for QD nanotherapy-such short wavelengths of light will be quickly scattered or absorbed near the surface of animal tissue. This lack of penetration would make it extremely challenging to use wide-bandgap materials to treat systemic infections. Red and near-infrared absorbing QDs would be far less susceptible to this issue. Therefore, near-infrared materials like cadmium telluride $(\mathrm{CdTe})$ $[19,20,24,29]$, copper indium sulfide $\left(\mathrm{CIS}_{2}\right)$ [19], indium phosphide (InP), and gallium arsenide (GaAs) could serve as good candidates for selective antimicrobial, material stability, cytotoxicity, and surfaces $[17,18]$. Using dopants and bandgap engineering, it is also possible to improve the suitability of some other materials. For instance, carbon QDs and silicon QDs have many reported biological applications in bio-imaging, cancer therapy, as well as some reports describing ROS-mediated therapy [38-41]. Depending on particle size and dopants,the optical properties of these materials can be

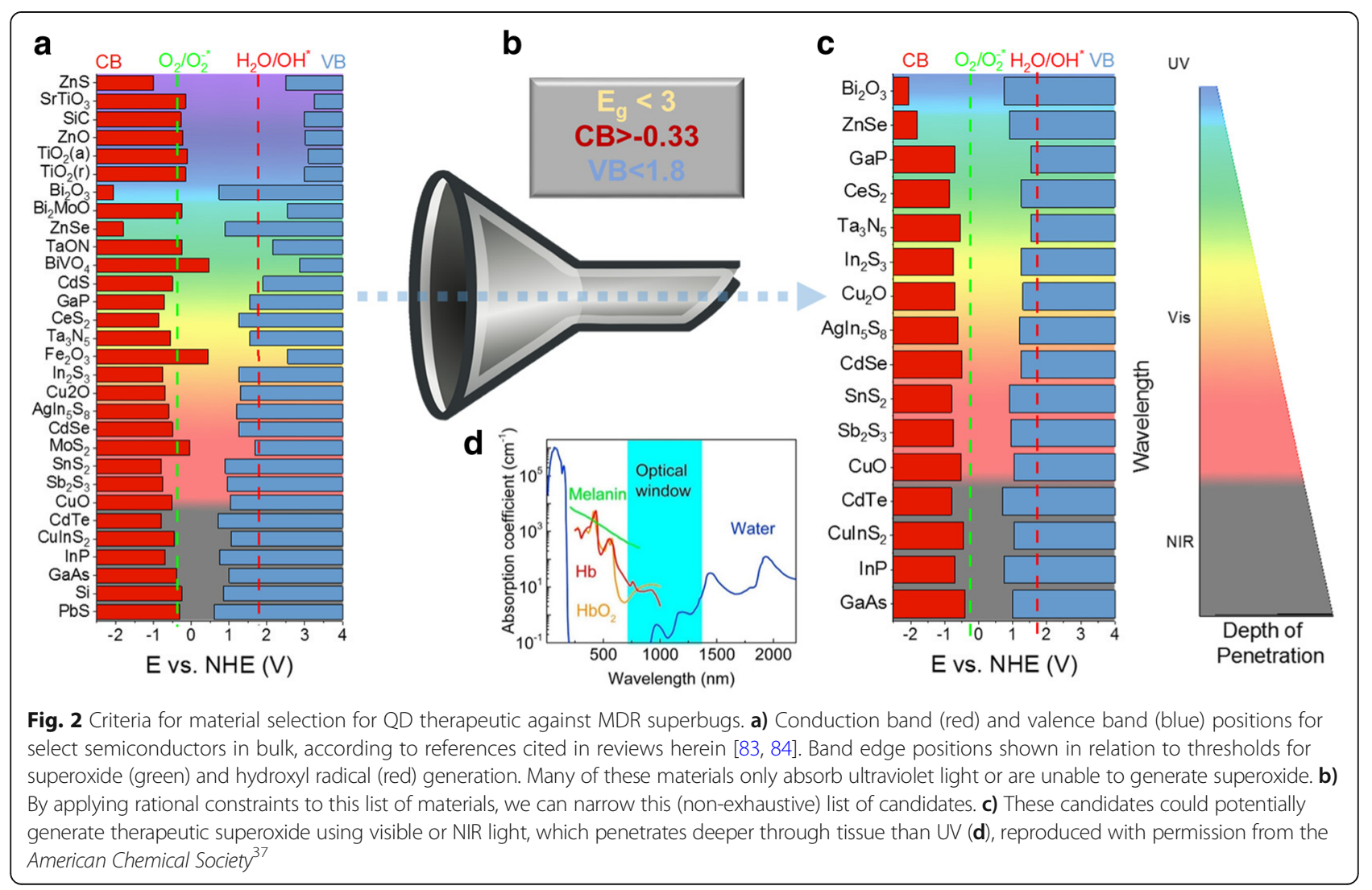


specifically tailored to decrease the energy of light required for photoactivation [42]. The same approach can also be extended to metal oxide materials.

Due to several contradictory reports of ROS generation and potential "therapeutic" action of two FDA-approved materials, zinc oxide $(\mathrm{ZnO})$ and titanium dioxide $\left(\mathrm{TiO}_{2}\right)$ QDs and nanoparticles [43-49], we evaluated their redox properties and demonstrated bandgap and redox state engineering approach proposed in this review. First, unmodified or undoped $\mathrm{ZnO}$ and $\mathrm{TiO}_{2}$ nanoparticles were tested using electron paramagnetic resonance (EPR) spectroscopy technique. In order to evaluate the short-lived radical species formed from redox chemistry, we used a spin-trapping method to form more stable adducts. Both $\mathrm{ZnO}$ and $\mathrm{TiO}_{2}$ nanoparticles showed only hydroxyl radical formation upon excitation with ultraviolet light above their bandgap (Fig. 3a,b). This would be problematic for potential nanotherapy because both ultraviolet light and hydroxyl radicals are indiscriminately toxic to all cells. Careful electrochemical measurements revealed that, while the $\mathrm{ZnO}$ reduction potential is too low for superoxide formation, its oxidation potential is very high-leading to hydroxyl generation upon light activation (Fig. 3c,e). Therefore, even if $\mathrm{ZnO}$ nanoparticles were doped with a cation (to reduce the nominal reduction potential) or anion (to reduce the oxidation potential), the visible light absorbing nanoparticles still could not form superoxide (Fig. 3e,g). This was further confirmed via electrochemical measurements by removing oxygen, where direct hole-injection into water leads to the formation of hydroxyl radical (Fig. 3c). Evaluation of $\mathrm{TiO}_{2}$ nanoparticles showed more promising results, however. While the oxidation potential of undoped $\mathrm{TiO}_{2}$ was too high, the reduction potential was suitably matched for superoxide formation (Fig. 3d, f). Therefore, anion-doped $\mathrm{TiO}_{2}$ nanoparticles, in principle, should form therapeutic superoxide. However, the presence of oxygen vacancies and resulting $\mathrm{Ti}^{3+}$ ions nominally present on this oxide material surface [50-52] catalyzes rapid Fenton chemistry to dismutate superoxide, converting it into toxic hydroxyl radicals [53]. To prevent such unwanted dismutation, we coated the surface of $\mathrm{TiO}_{2}$ nanoparticles with a zinc sulfide $(\mathrm{ZnS})$ shell, and saw significant superoxide formation (in visible light) using anion-doped (N-doped) $\mathrm{TiO}_{2}$ core/ZnS shell nanoparticles (Fig. 3f, h).

\section{Choosing the right material(s) for QD therapeutic}

While the choice of an appropriate redox-active material is important for selective therapeutic action, as shown above, the QD surface plays a key role in cellular photochemistry and biocompatibility. Many materials have appropriate redox properties to enable QD therapy, but present issues of colloidal stability or inherent cytotoxicity. A good solution to enable using such materials could be to use that material as a redox-active core, covered by a thin shell of biocompatible material [29]. Further, material cytotoxicity is often tied to a nanoparticle's physical size, hydrodynamic radius, and surface charge (zeta potential). These factors can directly affect a nanoparticle's affinity for surrounding biomolecules and tissue. For example, worsened zeta potential can hinder colloidal stability and potentially result in particle aggregation. This could lead to selective accumulation of QDs in some organs like kidney, spleen, and liver $[17,18]$, where the host cells have small pore sizes, but are quickly cleared through the rest of the organs and blood circulation. Nominally, QDs with a hydrodynamic diameter below $\sim 10 \mathrm{~nm}$ can be cleared from the body in in vivo animal tests. After accumulating in organs, due to lack of typical metabolism as seen in small molecules, one hypothesis suggests the potential for surface material leaching to occur, causing the QDs to "shrink" in size and clear away. This release of metal elements could present unpredictable and undesired host toxicity issues. Therefore, the choice of biocompatible material, at least on the QD surface, can be critical for successful application, reducing potential toxicity concerns for host cells. Evidence in support of this hypothesis from literature can be seen in Table 1 [85-104], where different core materials (like $\mathrm{CdSe}$ and $\mathrm{CdTe}$ ) when coated with other more benign/biocompatible materials, display a significant reduction in toxicity. We reviewed a number of such studies in literature with a wide range of sizes, hydrodynamic radius, and in vitro and in vivo studies. As a result, we found that even large QDs with significant retention made of/coated with less toxic elements, displayed much lower cytotoxicity. Further, materials that do not create any toxic ROS, such as hydroxyl or singlet oxygen, also displayed low cytotoxicity to the host cells. These materials could be used either as stable single-material QDs, or as coating/shell for QDs with a different core material better suited for redox perturbation.

\section{QD ligands, size, and clearance}

Comparing data from identical QDs/nanoparticles with different ligands, charge, and hence resulting different hydrodynamic radius, we observed significant differences in their retention and cytotoxicity (Table 2) [18-20], [105-109]. Notably, even across materials with different toxicity, e.g. CdSe, CdTe, and Au, surface ligands clearly influence retention and cytotoxicity. At identical QD/ nanoparticle core sizes, positively charged ligands (cysteamine) show indiscriminate adhesion to different negatively charged biomolecules, creating a protein "corona" that increases its hydrodynamic radius significantly. This effectively increases QD retention and resulting cytotoxicity $[17,18,29,54,55]$. Switching to negatively-charged 

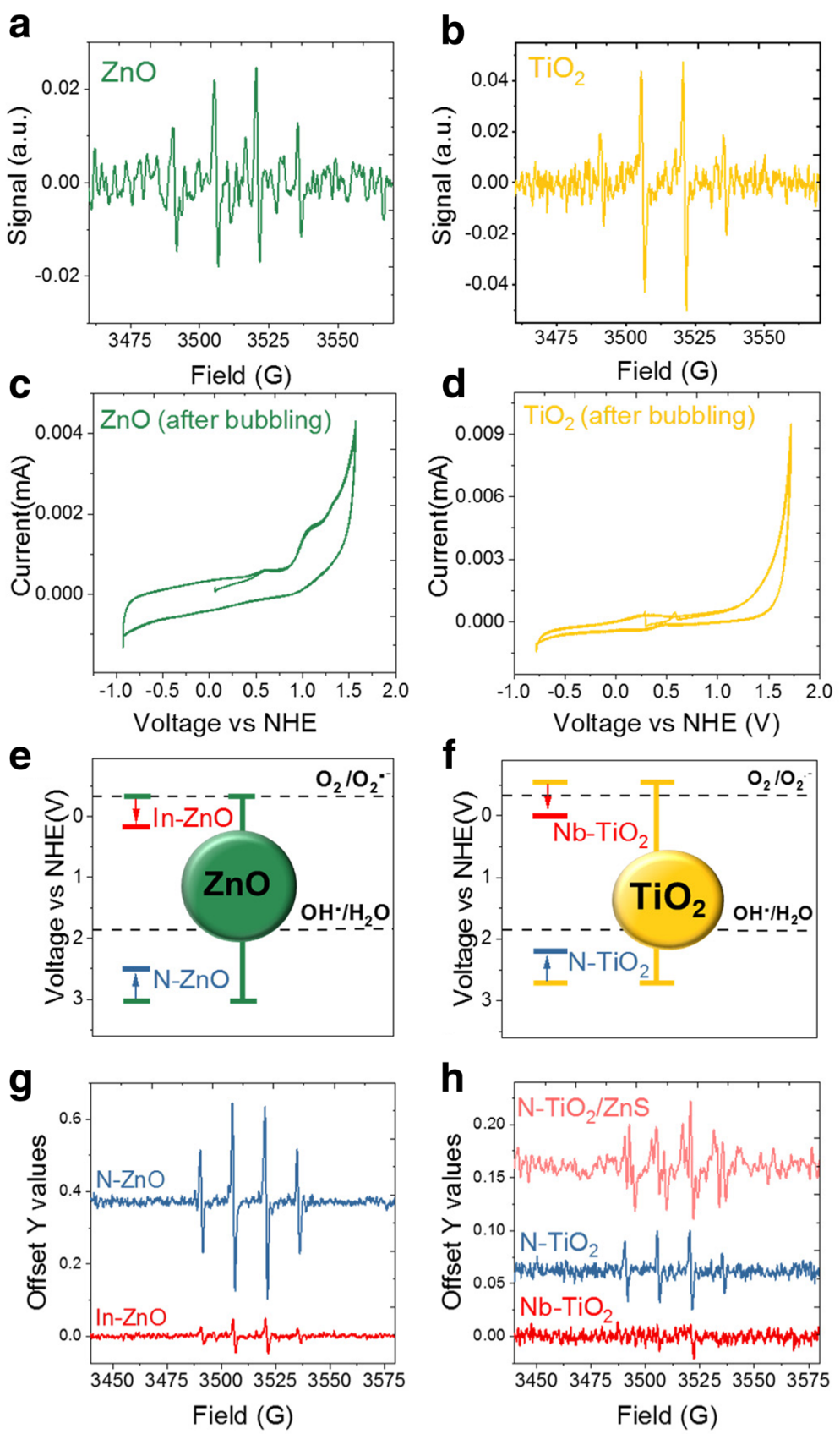

Fig. 3 Bandgap and redox state engineering for therapeutic radicals. a-b) EPR spectra for UV illuminated $\mathrm{ZnO}$ and $\mathrm{TiO}_{2}$ nanoparticles respectively, showing DMPO-OH peaks corresponding to the spin-trapped adduct of hydroxyl radicals. c-d) cyclic voltammograms for $\mathrm{ZnO}_{\text {and }} \mathrm{TiO}_{2}$, respectively, in deoxygenated water. Without a source of oxygen, $\mathrm{TiO}_{2}$ generates no radical signal but $\mathrm{ZnO}$ shows a peak corresponding to hydroxyl radicals - indicating superoxide-generating ability from $\mathrm{TiO}_{2}$ but not $\mathrm{ZnO}$. e-f) reduction and oxidation state positions for $\mathrm{ZnO}$ and $\mathrm{TiO}_{2}$, respectively, as well as the effects of doping. Anionic doping shifts the VB and cationic doping shifts the reduction potential. g-h) EPR spectra for engineered $\mathrm{ZnO}$ and $\mathrm{TiO}_{2}$, respectively. Anionic and cationic doping of $\mathrm{ZnO}$, as well as anionic doping of $\mathrm{TiO}_{2}$, yield hydroxyl production with visible light. Cationic doping of $\mathrm{TiO}_{2}$ shows no radical signal - indicating reliance on the reduction potential for superoxide generation. EPR spectra for $\mathrm{N}-\mathrm{TiO}_{2} / \mathrm{ZnS}$ shows clear DMPO-OOH peaks corresponding to the superoxide radical adduct

ligands (mercaptopropionic acid) at same/similar core size meanwhile reduces indiscriminate biomolecule attachment and lowers/eliminates toxicity. This ligand still results in higher hydrodynamic radius and higher retention, with low/moderate toxicity. However, a similarly sized zwitterionic-ligand (cysteamine) results in low hydrodynamic radius and toxicity. These findings can be explained by the lack of formation of a protein corona 
Table 1 Review of in vitro and in vivo toxicity reported for relevant core/shell QDs [85-104]
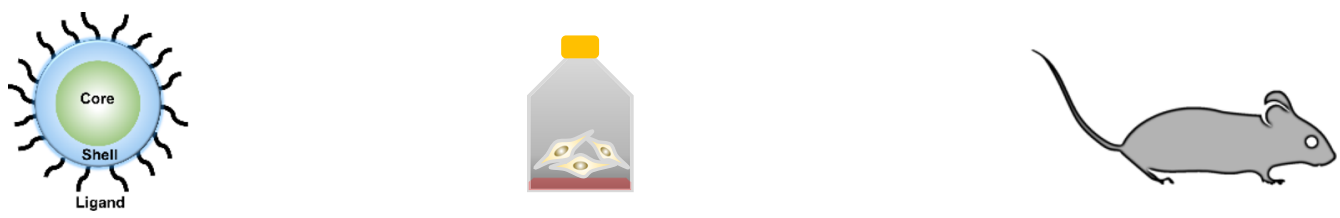

\begin{tabular}{ll}
\hline $\begin{array}{l}\text { Nanoparticle } \\
\text { Core/Shell }\end{array}$ & In vitro \\
Effect (concentration) \\
\hline CdSe & $\begin{array}{l}\text { Nontoxic without oxidation. }{ }^{85} \\
\text { Toxic after strong oxidation }(6 \mu \mathrm{g} / \mathrm{ml})^{85} \\
\end{array}$ \\
& Nontoxic (sub-100 $\mathrm{nM})^{19}$
\end{tabular}

In vivo

CdSe/CdS $\quad \operatorname{LD}_{50}(50-100 \mathrm{nM})^{87}$

$\begin{array}{ll}\text { CdSe } / Z n S & \text { Nontoxic at small green emitting size } \\ \text { CdTe } & (240 \mathrm{nM})^{89} \\ & \mathrm{LD}_{50}(40 \mu \mu \mathrm{g} / \mathrm{ml})^{90} \\ & \text { Decrease in metabolic activity }(10 \\ \mu \mathrm{g} / \mathrm{ml})^{91} & \mathrm{LD}_{25}(40 \mu \mathrm{g} / \mathrm{ml})^{92} \\ & \text { Nontoxic }(160 \mathrm{nM})^{19,20} \\ & 50 \% \text { decrease in metabolic activity }(50 \\ & \mu \mathrm{g} / \mathrm{ml})^{93}\end{array}$

[Animal] effect (dose)

[Mouse] Injury to liver, but not spleen or kidney $(200 \mathrm{nM})^{86}$

$\begin{array}{ll}\mathbf{C d T e} / \mathrm{ZnSe} & \text { Nontoxic }(1000 \mu \mathrm{g} / \mathrm{ml})^{94} \\ \mathbf{C d T e} / \mathbf{Z n T e} & \text { Nontoxic }(150 \mu \mathrm{g} / \mathrm{ml})^{90} \\ \mathbf{C u I n S}_{2} & \text { LD }_{50}(300 \mu \mathrm{g} / \mathrm{ml})^{95} \\ \mathbf{I n G a P} / \mathbf{Z n S} & \text { No significant cytotoxicity }(200 \mathrm{nM})^{89} \\ \mathbf{I n P} / \mathbf{Z n S} & \text { Nontoxic }(1000 \mu \mathrm{g} / \mathrm{ml})^{97} \\ \mathbf{C u} \mathbf{O} & \text { Nontoxic }(160 \mu \mathrm{g} / \mathrm{ml})^{98} \\ \mathbf{G a A s} & >90 \% \text { toxic }(40 \mu \mathrm{g} / \mathrm{ml})^{100} \\ & \text { Acutely toxic as seeding surface for HeLa } \\ \mathbf{A g}_{2} \mathbf{S} & \text { unless coated with peptide } \\ \mathbf{Z n S} & \text { Decreased viability- } 20 \%(200 \mu \mathrm{g} / \mathrm{ml}) \\ & 50 \%(1000 \mu \mathrm{g} / \mathrm{ml}) \\ & \text { Nontoxic }(100 \mu \mathrm{M})^{103} \\ & \text { Nontoxic }(1600 \mu \mathrm{g} / \mathrm{ml})^{104}\end{array}$

[Mouse] Significant body weight change, but no clinical signs ( 25 $\mathrm{mg} / \mathrm{kg})^{88}$

[Rat] Nontoxic (15 nmol/rat)

[Mouse] Decrease in liver size after 28 days $(16.5 \mathrm{mg} / \mathrm{kg})^{92}$

[Mouse] Nontoxic $(5 \mathrm{mg} / \mathrm{kg})^{94}$

[Mouse] Nontoxic $(5 \mathrm{mg} / \mathrm{kg})^{90}$

[Mouse] Nontoxic during imaging study ( 1 to $2 \mu \mathrm{mol}$, or $0.5 \mathrm{mg})^{95,96}$

[Rat] Nontoxic $(50 \mathrm{mg} / \mathrm{kg})^{99}$

[Rat] Accumulation of arsenic after 14 days $(10 \mathrm{mg} / \mathrm{kg})^{102}$

[Mouse] Nontoxic and excreted in feces $(20 \mathrm{mg} / \mathrm{kg})^{104}$

and higher rates of renal clearance in in vivo animal studies. This points to a clear strategy of controlling the QD core/shell size, along with ligand and charge, so that the total hydrodynamic diameter remains below 10-15 $\mathrm{nm}$. Taken together, this 3-layer design approach consists of: 1) QD made with core material with tuned reduction-oxidation potentials for selective generation of superoxide for as antimicrobial for MDR superbugs; 2) non-toxic and biocompatible shell core or shell material, resulting in high chemical stability and low material leaching and cytotoxicity; and 3) ligand design (zwitterionic) to maintain a low-hydrodynamic radius, high rates of clearance, and low toxicity, can be employed for a suitable therapeutic bottom-up design strategy for redox QD therapies.

\section{Future outlook/approaches}

Addressing host toxicity

There are three major potential sources of toxicity for the host mammalian cells that the current and future non-traditional QD therapeutics need to address: 1) Acute material toxicity leading to loss of host cell 
Table 2 Review of common charged ligands and reported effects on biodistribution and toxicity [18-20], [105-109]

\begin{tabular}{|c|c|c|c|c|c|}
\hline Nanoparticle & $\begin{array}{l}\text { Ligand } \\
\text { (charge) }\end{array}$ & $\begin{array}{c}\text { Hydrodynamic } \\
\text { Diameter* }\end{array}$ & Clearance & Retention & Toxicity \\
\hline \multirow{6}{*}{$\begin{array}{l}\mathrm{CdSe}, \mathrm{CdTe} \\
(\mathrm{D}=2.8-4.3 \\
\mathrm{nm})\end{array}$} & \multirow{3}{*}{$\begin{array}{l}\text { DHLA, MPA } \\
\text { (negative) }^{18,105-} \\
107\end{array}$} & \multirow[t]{3}{*}{$>15 \mathrm{~nm}$} & \multirow[t]{3}{*}{ None $^{18,106}$} & Liver, lung, spleen ${ }^{18}$ & \multirow[t]{3}{*}{$\begin{array}{c}\mathrm{No}^{19,20,29} \\
, 107,108\end{array}$} \\
\hline & & & & $\begin{array}{l}\text { Spleen, liver, } \\
\text { kidneys }^{105}\end{array}$ & \\
\hline & & & & $\begin{array}{l}\text { Retained at the } \\
\text { injection site (lymph } \\
\text { nodes) })^{106}\end{array}$ & \\
\hline & \multirow{2}{*}{$\begin{array}{l}\text { Cysteamine, } \\
\text { AUT } \\
\text { (positive) }^{18,107}\end{array}$} & \multirow[t]{2}{*}{$>15 \mathrm{~nm}$} & \multirow[t]{2}{*}{ None $^{18}$} & Liver, lung, spleen ${ }^{18}$ & \multirow[t]{2}{*}{$\begin{array}{c}\text { Yes }_{8}^{107,10} \\
\end{array}$} \\
\hline & & & & Kidney, brain ${ }^{108}$ & \\
\hline & 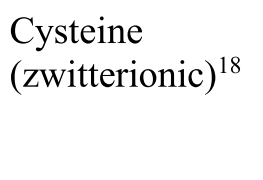 & $<5.5 \mathrm{~nm}$ & $\begin{array}{l}50 \% \\
\text { (renal) in } 4 \\
\text { hours }^{18}\end{array}$ & $\begin{array}{l}\text { Most retention in } \\
\text { bladder, presumably } \\
\text { before excreting } \\
\text { through urine }^{18}\end{array}$ & $\mathrm{No}^{107}$ \\
\hline \multirow{5}{*}{$\begin{array}{l}\mathrm{Au} \\
\text { (varying core } \\
\text { size) }\end{array}$} & $\begin{array}{l}\text { Cysteamine } \\
\text { (positive) }\end{array}$ & - & $\begin{array}{l}\sim 22 \% \\
(24 \mathrm{~h})\end{array}$ & $\begin{array}{l}\text { Mostly in spleen, } \\
\text { liver, lungs }\end{array}$ & Yes \\
\hline & TGA (negative) & - & $\begin{array}{l}\sim 19 \% \\
(24 \mathrm{~h})\end{array}$ & $\begin{array}{l}\text { Mostly in liver, } \\
\text { spleen, lungs }\end{array}$ & No \\
\hline & $\begin{array}{l}\text { TPPMS } \\
\text { (neutral) }\end{array}$ & $\begin{array}{c}<5.5 \mathrm{~nm} \\
\left(\mathrm{D}_{\text {core }}=1.4 \mathrm{~nm}\right)\end{array}$ & $\begin{array}{l}\sim 10 \% \\
(24 \mathrm{~h})\end{array}$ & $\begin{array}{l}\text { Mostly in liver, } \\
\text { spleen, kidneys }\end{array}$ & - \\
\hline & $\begin{array}{l}\text { TPPMS } \\
\text { (neutral) }\end{array}$ & $\begin{array}{c}<15 \mathrm{~nm} \\
\left(D_{\text {core }}=5 \mathrm{~nm}\right)\end{array}$ & $\begin{array}{l}\sim 13 \% \\
(24 \mathrm{~h})\end{array}$ & $\begin{array}{l}\text { Mostly in liver, } \\
\text { spleen. Less in } \\
\text { kidneys, more in } \\
\text { liver relative to small } \\
\text { sizes }\end{array}$ & - \\
\hline & $\begin{array}{l}\text { TPPMS } \\
\text { (neutral) }\end{array}$ & $\begin{array}{c}>85 \mathrm{~nm} \\
\left(\mathrm{D}_{\text {core }}=80 \mathrm{~nm}\right)\end{array}$ & $\begin{array}{l}\sim 14 \% \\
(24 \mathrm{~h})\end{array}$ & $\begin{array}{l}\text { Retention in liver, } \\
\text { spleen. More } \\
\text { retention in blood } \\
\text { relative to other sizes }\end{array}$ & - \\
\hline \multicolumn{5}{|c|}{$\begin{array}{l}\text { DHLA: Dihydrolipoic acid } \\
\text { MPA: 3-mercaptopropionic acid } \\
\text { AUT: Amino undecanethiol } \\
\text { TGA: Thioglycolic acid } \\
\text { TPPMS: Triphenylphosphine monosulfonate }\end{array}$} & \\
\hline
\end{tabular}

viability or growth; 2) Oxidative stress; and 3) DNA damage and carcinogenesis. To address these concerns, the QD therapeutics first need to address acute cytotoxicity concerns in in vitro screenings, and only advance candidates that show clear differences in MIC values for the host and pathogen cells. This can be 
established by designing the mechanism of action after careful consideration of potential vulnerabilities in the pathogen's cellular environment and metabolism. This, therefore, leads to a more directed and dynamic approach to counter the adaptive resistance in these MDR pathogens. Similarly, the use of specific ROS like superoxide-which can be selectively toxic to iron-sequestering pathogens-creates a clear window for differences in MIC values between host and pathogens. This therapeutic window of concentration has been successfully identified and utilized as a therapeutic in in vitro studies to target MDR pathogens, while preserving host viability and growth. Further experiments are needed to determine the transcriptomic response to superoxide therapy. More specifically, this is necessary to understand how oxidative stress from the proposed treatment affects the host. So far, the experimental evidence in literature points to non-perturbative stress response of the host to specific ROS like superoxide, and to a mechanism of action limited primarily to enzyme deactivation and indiscriminate DNA/RNA damage or genotoxicity.

To further alleviate these concerns, our lab is developing two nanoparticle therapeutic adjuvant and "countermeasures", made from FDA approved materials, to be supplied with the QD therapeutic: a) larger-sized adjuvant nanoparticles $(<20-50 \mathrm{~nm})$ which can evoke a stronger immune response, aiding the QD nanotherapeutic [56, 57], by acting as "Nano-Immunotherapy" (Fig. 4a); and b) 20-50 nm nanoparticles coated with [Fe-S] cluster [58] complexes as countermeasures, for size-selective uptake in host cells (Fig. $4 \mathrm{~b}$ ), to reduce the superoxide concentrations and ROS stress in the host and protect them against any potential toxic mechanism (Fig. 4a).

\section{Nano-Immunotherapeutics}

are a class of new immunomodulatory materials, where their physicochemical properties: size, shape, surface charge, molecular weight, roughness, and hydrophobicity, are used to mimic normal cellular components and evade or suppress immune response (immune-evasive or immune-suppressing), or designed to inflame the host immune response for potential therapeutic effect (immune-activating materials) [56, 57]. For instnace, smaller nanoparticles have higher uptake and trafficking, allowing them to reach the lymph nodes-evoking higher levels of surface maturation markers and inflammatory cytokine secretion [59-61]. Further, asymmetrical shapes, such as nanorods, show similar trends in their immune response: Nanorods with similar radius but smaller length show higher uptake [61]. But longer

a

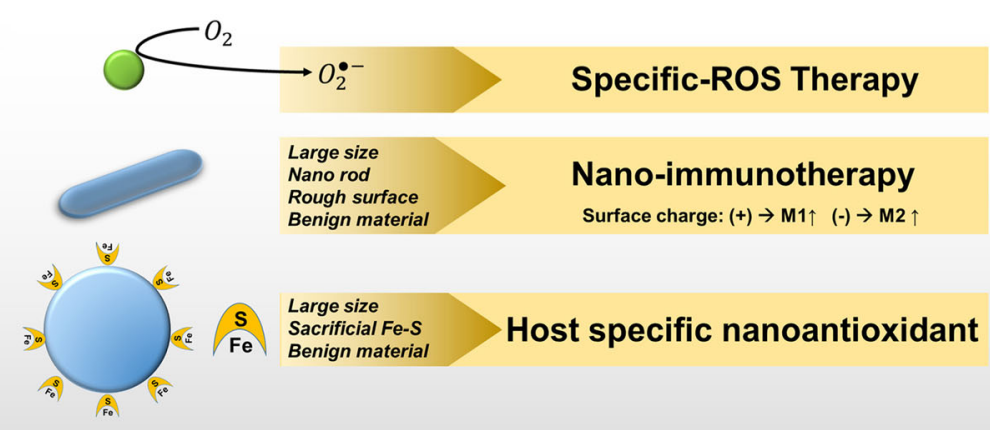

b

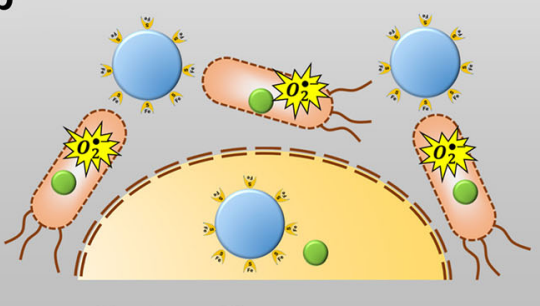

C

Transcriptomic vs. Proteomic

Host-specific countermeasure
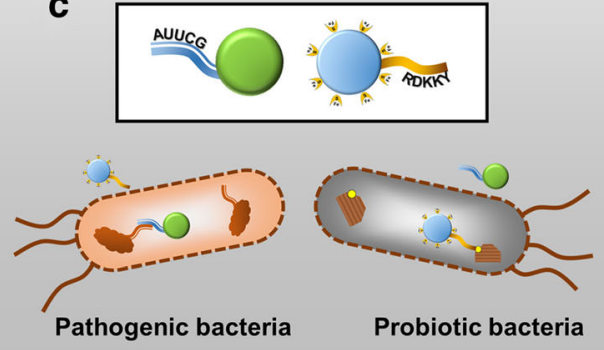

Fig. 4 Addressing QD toxicity and future directions. a) Schematic and summary of three proposed types of non-traditional therapeutic, adjuvant, and countermeasure nanoparticles. QD therapeutics (top) using superoxide generation; Nano-immunotherapy (middle) using 20-50 nm benign nanorods to trigger an immune response; and a countermeasure (bottom) using large or small benign nanoparticles coordinated with Fe-S to serve as a host-specific nano-antioxidant. b) Depiction of host-specific protection using the larger nanoparticles coated with [Fe-S] clusters as countermeasures against the superoxide ROS stress from QD therapeutic. c) Depiction of probiotic-specific protection using transcriptomic/ proteomic targeting with countermeasure nanoparticles 
nanorods induced a higher inflammatory response (IL-1 $\alpha$ and TNF- $\alpha$ ) because of frustrated phagocytic interactions with cells, due to their larger size [62]. Increasing the hydrophobicity of the nanomaterials surface identifies them as foreign, and potentially dangerous materials, by the immune system. This increases the gene-expression of pro-inflammatory cytokines [63]. Coating the QD or other nanomaterial surfaces with hydrophilic molecules reduces the surface protein adsorption and decreases interaction with immune cells, thereby reducing immunomodulatory response. Studies on the effect of the surface charge have shown confounding effects with other dominant physiochemical properties. Gold nanorods with positive surface charge (amine-terminated ligands) exhibit expression of anti-inflammatory surface antigens and negatively-charged (carboxylic acid-terminated ligands) surfaces induced expression of pro-inflammatory genes [64]. However, other studies have concluded that negatively-charged amino acid residues can sometimes prevent uptake of long fibrillized peptide materials by antigen-presenting cells, and hence prevent presentation of epitope peptides-thereby inhibiting immune function [65]. Overall, zwitterionic ligands or surface charges prevent accumulation/adsorption of biomolecules like proteins (biofouling), thereby evading foreign-body response $[56,57,66]$. These elements of immunomodulation were used in our QD design (small size, spherical shape, small hydrophilic ligands, and zwitterionic surface charge). By reducing the potential of non-specific inflammation of the host immune system, the potential side effects of the QD therapeutic nanoparticles could be avoided.

Other aspects of immune modulation using physiochemical properties of nanoparticles depend on their molecular weight and surface roughness. The effect of surface topography at the nanoscale, along with surface chemistry was used to understand the innate immune response. While surface acidity has a larger role in immunomodulation, surface roughness directly is correlated with enhanced matrix metalloproteinase-9 production by primary neutrophils, and a decrease in the pro-inflammatory cytokine secretion from primary macrophages [67]. This immunomodulation via surface roughness could be attributed to a reduction in inflammation and increased healing on encountering rough surfaces.

Based on the design rules summarized here, the adjuvant Nano-Immunotherapeutic will: 1) be larger-size nanoparticles than QD therapeutics $(<20-50 \mathrm{~nm})$, but small enough that they easily transport to reach lymph nodes $[68,69]$ and initiates/upregulates the innate immune response of the body [59], to aid the QD therapeutic and fight pathogens; 2) be shaped as short nanorods, rather than spherical nanoparticles, for preferential uptake and stronger immunomodulation [64]; 3) have induced surface roughness and hydrophobicity [63, 70, 71]; and 4) have a designed surface charge to tune the inflammatory response (Fig. 4a) [64, 72, 73]. These nano-immunotherapeutic nanoparticles could, reversibly, also be used to downregulate the immune response and inflammation, in case the QD nanotherapeutic has any adverse/side-effects due to retention of over-activity. Further, the size-selected uptake of nanoparticles acting as counter-measures for the host cells would be designed to counter any ROS stress, deactivation of superoxide in the host, and reduce any potential for genotoxicity from the QD therapeutic, using a coating of [Fe-S] clusters on these nanoparticles (Fig. 4a,b) [58]. Such coatings can be easily created using a hydrophobic-hydrophilic surface interaction, and will be used with a small subset of FDA approved materials, like $\mathrm{ZnO}, \mathrm{TiO}_{2}$, or silica nanoparticles.

\section{Improving selective uptake in different cell-types (host and pathogen)}

One future approach to improving QD therapeutics is targeting selective uptake between host and pathogen (Fig. 4b), as well as between different pathogens (e.g. pathogenic vs. probiotics, Fig. 4c). Size can be an important factor in tuning uptake between host and pathogens [74, 75]. By selecting for the appropriate size, a QD therapy can selectively generate therapeutic superoxide and induce pathogen-killing, while protecting the host cells using nano-countermeasures. For selectivity between different types of bacteria, such as pathogenic strains and gut microbiota, target specificity must be considered. Reaching such targets would require the identification of the genomic, transcriptomic, or proteomic factors that separate the distinct strains. QD therapeutics can be easily coated with peptides or DNA/RNA molecules with appropriate target sequences (Fig. 4c) [76-81]. Using this methodology, similar sized pathogen-targeted QDs can be selectively uptaken by the pathogens as a QD therapeutic, while similarly sized countermeasures can be selectively transported into the probiotic bacteria, further protecting them from adverse effects of the QD therapeutic. This approach can boost the efficacy of QD therapeutics while reducing potential side-effects. Importantly, the window of QD therapeutic flux between host and pathogens can be further expanded to provide more immediate and effective relief to patients.

\section{Conclusions}

In conclusion, this review summarizes the potential, existing, state-of-the-art, and future outlook for an emerging class of radical QD therapeutics. Here, we specifically sought to show several aspects of QD design, geared towards treating MDR superbug infections. By tailoring the stimuli-triggered photochemistry, inherent materials, and chosen mechanism of action, a bottom-up rational design 
strategy was outlined for the QD therapeutic. This approach begins with a mechanism of redox action that targets a specific vulnerability in the pathogen compared to the host cells. Achieving such biological specificity is important to preserve the healthy host cells and offer the safest possible treatment. Selecting a redox mechanism is then followed by careful material selection and 3-layered design to optimize safety and efficacy. The proposed approach will be bolstered by further work to develop a nanoparticle adjuvant, such as nano-immunotherapeutics, and nano-countermeasures for host and probiotic cells. While the work presented here shows a design approach to radical therapy for countering adaptive resistance in bacteria, the same approach can be easily extended to a range of different diseases (e.g. cancer), as well as to precision medicine. For precise treatment of diseases at the scale of molecular biology, healthy and diseased cells can be distinguished from each other, and QD interactions can be tailored to exploit those differences. Using this emerging Quantum Biology approach being developed in our group and by other researchers, a new rational design strategy can be achieved for therapies that are dynamic or adaptive, and can be quickly tailored at the atomic and molecular level. The semiconductor QDs discussed here can be leveraged to rationally design effective treatments, using the governing principles described in this review. Progress in this area could stimulate the development of a new class of smart therapies, reduce the time required for regulatory approval by using small tweaks in atomic and molecular arrangement of an approved QD therapeutic, and enable researchers to deploy their inventions to address a rapidly emerging class of adaptive or dynamic diseases.

\section{Abbreviations}

$\mathrm{Ag}_{2} \mathrm{~S}$ : Silver sulfide; AUT: Amino undecanethiol; CdS: Cadmium sulfide; CdSe: Cadmium selenide; CdTe: Cadmium telluride; CulnS 2 : Copper indium sulfide; $\mathrm{Cu}_{2} \mathrm{O}$ : Copper oxide; DHLA: Dihyrolipoic acid; DNA: Deoxyribonucleic acid; EPR: Electron paramagnetic resonance; FDA: Food and Drug Administration; Fe-S: Iron-sulfur; GaAs: Gallium arsenide; InGaP: Indium gallium phosphide; InP: Indium phosphide; MDR: Multidrug-resistant; MIC: Minimum inhibitory concentration; MPA: 3-mercaptopropionic acid; NHE: Normal hydrogen electrode; QD: Quantum dot; RNA: Ribonucleic acid; RNS: Reactive nitrogen species; ROS: Reactive oxygen species; TGA: Thioglycolic acid; $\mathrm{TiO}_{2}$ : Titanium dioxide; TPPMS: Triphenylphosphine monosulfonate; ZnO: Zinc oxide; ZnS: Zinc sulfide; ZnSe: Zinc selenide; ZnTe: Zinc telluride

\section{Acknowledgement}

The authors acknowledge financial support from National Scince Foundation (NSF) CAREER CBET-1351281, and William M. Keck Foundation Research Award.

\section{Availability of data and materials}

All data generated or analyzed during this study are included in this published article.

\section{Authors' contributions}

All authors wrote and edited the manuscript, have read and approved the final manuscript.
Ethics approval and consent to participate

Not applicable.

\section{Consent for publication}

This is an open-access article distributed under the terms of the Creative Commons Attribution Non-Commercial 4.0 International License (http:// creativecommons.org/licenses/by-nc/4.0) which permits copy and redistribute the material just in non-commercial usages, provided the original work is properly cited.

\section{Competing interests}

The authors declare that they have no competing interests.

\section{Publisher's Note}

Springer Nature remains neutral with regard to jurisdictional claims in published maps and institutional affiliations.

\section{Author details}

${ }^{1}$ Chemical and Biological Engineering, University of Colorado Boulder, Boulder, CO 80303, USA. ${ }^{2}$ Renewable and Sustainable Energy Institute, University of Colorado Boulder, Boulder, CO 80303, USA. ${ }^{3}$ Materials Science and Engineering, University of Colorado Boulder, Boulder, CO 80303, USA.

Received: 18 February 2019 Accepted: 21 April 2019

Published online: 29 May 2019

\section{References}

1. Albert $L L$, Lehninger AL. Lehninger principles of biochemistry / David L. Michael M. Cox: Nelson; 2005.

2. Crack JC, Green J, Cheesman MR, Le Brun NE, Thomson AJ. Superoxidemediated amplification of the oxygen-induced switch from [4Fe-4S] to [2Fe2S] clusters in the transcriptional regulator FNR. Proc Natl Acad Sci U S A. 2007;104(7):2092-7.

3. Zheng M, Aslund F, Storz G. Activation of the OxyR Transcription Factor by Reversible Disulfide Bond Formation. Science (80-. ). 1998;279(5357):1718-22.

4. Lee J-WW, Helmann JD. The PerR transcription factor senses $\mathrm{H} 2 \mathrm{O} 2$ by metal-catalysed Histidine oxidation. Nature. 2006;440(7082):363-7.

5. Fuangthong M, Atichartpongkul $\mathrm{S}$, Mongkolsuk S, Helmann JD. OhrR is a repressor of ohrA, a key organic Hydroperoxide resistance determinant in Bacillus Subtilis. J Bacteriol. 2001;183(14):4134-41.

6. Bogdan C. Nitric oxide and the immune response. Nat Immunol. 2001;2(10): 907-16.

7. Vatansever F, de Melo WCMA, Avci P, Vecchio D, Sadasivam M, Gupta A Chandran R, Karimi M, Parizotto NA, Yin R, et al. Antimicrobial Strategies Centered around Reactive Oxygen Species - Bactericidal Antibiotics, Photodynamic Therapy, and beyond. FEMS microbiology reviews. 2013;37: 955-89.

8. Davies MJ. The Oxidative Environment and Protein Damage. Biochimica et Biophysica Acta (BBA)-Proteins and Proteomics. 2005;1703:93-109.

9. Davies MJ. Singlet oxygen-mediated damage to proteins and its consequences. Biochem Biophys Res Commun. 2003;305(3):761-70.

10. Finkel T, Holbrook NJ. Oxidants, oxidative stress and the biology of ageing. Nature. 2000;408(6809):239-47.

11. Radi R. Peroxynitrite, a Stealthy Biological Oxidant. J Biol Chem. 2013;288: 26464-72.

12. Pacher P, Beckman JS, Liaudet L. Nitric oxide and Peroxynitrite in health and disease. Physiol Rev. 2007;87(1):315-424.

13. Candeias LP, Wardman P. Introduction to Fenton chemistry. Radiat Res. 2013;145(5):523-31.

14. Bielski BHJ, Allen $\mathrm{AO}$, Schwarz HA. Mechanism of the disproportionation of superoxide radicals. J Am Chem Soc. 1981;103(12):3516-8.

15. McCord JM. Fridovich. Hemoglobin: I. Superoxide Dismutase; 1969. No. 22

16. Pryor WA, Squadrito GL. The chemistry of Peroxynitrite: a product from the reaction of nitric oxide with superoxide. Am J Phys. 1995;268(5 Pt 1):L699-722.

17. Yong K-TT, Law W-CC, Hu R, Ye L, Liu L, Swihart MT, Prasad PN. Nanotoxicity assessment of quantum dots: from cellular to primate studies. Chem Soc Rev. 2013;42(3):1236-50.

18. Choi HS, Liu W, Misra P, Tanaka E, Zimmer JP, Ipe BI, Bawendi MG, Frangioni JV. Renal clearance of quantum dots. Nat Biotechnol. 2007;25(10):1165-70. 
19. Courtney CM, Goodman SM, McDaniel JA, Madinger NE, Chatterjee A, Nagpal P. Photoexcited quantum dots for killing multidrug-resistant Bacteria. Nat Mater. 2016;15(5):529-34.

20. Courtney, C. M.; Goodman, S.; Nagy, T.; Levy, M.; Bhusal, P.; Madinger NE, Detweiler CS, Nagpal P, Chatterjee A. Potentiating Clinical Drug Resistant Bacteria via Stimuli-Activated Superoxide Generation. Sci. Adv. 2017, 3 (October), e1701776.

21. Loo C, Lowery A, Halas N, West J, Drezek R. Immunotargeted Nanoshells for integrated Cancer imaging and therapy. Nano Lett. 2005;5(4):709-11.

22. Di Meo, S.; Reed, T. T.; Venditti, P.; Victor, V. M. Role of ROS and RNS Sources in Physiological and Pathological Conditions; 2016; Vol. 2016.

23. D'Autréaux B, Toledano MB. ROS as Signalling molecules: mechanisms that generate specificity in ROS homeostasis. Nat Rev Mol Cell Biol. 2007;8(10): 813-24.

24. Levy M, Courtney CM, Chowdhury PP, Ding Y, Grey EL, Goodman SM, Chatterjee A, Nagpal P. Assessing different reactive oxygen species as potential antibiotics: selectivity of intracellular superoxide generation using quantum dots. Bio Mater: ACS Appl; 2018.

25. Imlay JA. Pathways of oxidative damage. Annu Rev Microbiol. 2003;57(1): 395-418.

26. Imlay JA, Linn S. DNA damage and oxygen radical toxicity. Science. 1988; 240(4857):1302-9.

27. Nakamura J, Purvis ER, Swenberg JA. Micromolar Concentrations of Hydrogen Peroxide Induce Oxidative DNA Lesions More Efficiently than Millimolar Concentrations in Mammalian Cells. Nucleic Acids Res. 2003:1790-5.

28. Li C-Q, Pang B, Kiziltepe T, Trudel LJ, Engelward BP, Dedon PC, Wogan GN. Threshold effects of nitric oxide-induced toxicity and cellular responses in wild-type and p53-null human Lymphoblastoid cells. Chem Res Toxicol. 2006;19(3):399-406.

29. Goodman SM, Levy M, Li F-F, Ding Y, Courtney CM, Chowdhury PP, Erbse A, Chatterjee A, Nagpal P. Designing superoxide-generating quantum dots for selective light-activated Nanotherapy. Front Chem. 2018;6:46.

30. Imlay JA. Iron-Sulphur Clusters and the Problem with Oxygen. Mol Microbiol. 2006:1073-82.

31. Iglewski, B.; Clark V. Molecular Basis of Bacterial Pathogenesis; 1990.

32. Pan $X$, Yang $Y$, Zhang J-R. Molecular basis of host specificity in human pathogenic Bacteria. Emerg Microbes Infect. 2014;3(3):e23.

33. Winterbourn CC. Reconciling the Chemistry and Biology of Reactive Oxygen Species. Nature Chemical Biology. 2008:278-86.

34. Sawyer DT, Valentine JS. How super is superoxide? Acc Chem Res. 1981 ; 14(12):393-400.

35. Sawyer DT, Valentine JS, Fridovich I, Sawyer DT, Valentine JS, Fridovich I. How innocuous is superoxide? Comments. Acc Chem Res. 1982;15(7):200.

36. Sun Q-C, Ding YC, Sagar DM, Nagpal P. Photon Upconversion towards applications in energy conversion and bioimaging. Prog Surf Sci. 2017;92(4): 281-316.

37. Sun QC, Mundoor H, Ribot JC, Singh V, Smalyukh II, Nagpal P. Plasmonenhanced energy transfer for improved Upconversion of infrared radiation in doped-lanthanide Nanocrystals. Nano Lett. 2014;14(1):101-6.

38. Tian Z, Yao X, Hanagata N, Liu J, Zhu Y. Mesoporous silica nanoparticles capped with Graphene quantum dots for potential chemo-Photothermal synergistic Cancer therapy. Langmuir. 2016;33(2):591-9.

39. Chinnathambi S, Chen S, Ganesan S, Hanagata N. Silicon quantum dots for biological applications. Adv. Healthc. Mater. 2014;3(1):10-29.

40. Gara PMD, Garabano NI, Portoles MJL, Moreno MS, Dodat D, Casas OR, Gonzalez MC, Kotler ML. ROS Enhancement by Silicon Nanoparticles in XRay Irradiated Aqueous Suspensions and in Glioma C6 Cells. J. Nanoparticle Res. 2012;14(3):741

41. Hassan M, Gomes VG, Dehghani A, Ardekani SM. Engineering carbon quantum dots for Photomediated Theranostics. Nano Res. 2018;11(1):1-41.

42. Abdelhameed M, Martir DR, Chen S, Xu WZ, Oyeneye OO, Chakrabarti S, Zysman-Colman E, Charpentier PA. Tuning the optical properties of silicon quantum dots via surface functionalization with conjugated aromatic Fluorophores. Sci Rep. 2018;8(1):1-10.

43. Premanathan M, Karthikeyan K, Jeyasubramanian K, Manivannan G. Selective toxicity of $\mathrm{ZnO}$ nanoparticles toward gram-positive Bacteria and Cancer cells by apoptosis through lipid peroxidation. Biol. Med: Nanomedicine Nanotechnology; 2011

44. Lakshmi Prasanna V, Vijayaraghavan R. Insight into the mechanism of antibacterial activity of $\mathrm{ZnO}$ : surface defects mediated reactive oxygen species even in the dark. Langmuir. 2015.
45. Sirelkhatim A, Mahmud S, Seeni A, Kaus NHM, Ann LC, Bakhori SKM, Hasan $H$, Mohamad D. Review on Zinc Oxide Nanoparticles: Antibacterial Activity and Toxicity Mechanism. Nano-Micro Letters. 2015:219-42.

46. Heinlaan M, Ivask A, Blinova I, Dubourguier HC, Kahru A. Toxicity of Nanosized and bulk $\mathrm{ZnO}, \mathrm{CuO}$ and $\mathrm{TiO} 2$ to Bacteria Vibrio Fischeri and crustaceans daphnia magna and Thamnocephalus Platyurus. Chemosphere. 2008.

47. Song W, Zhang J, Guo J, Zhang J, Ding F, Li L, Sun Z. Role of the dissolved zinc ion and reactive oxygen species in cytotoxicity of $\mathrm{ZnO}$ nanoparticles. Toxicol Lett. 2010;199(3):389-97.

48. Lin X, Li J, Ma S, Liu G, Yang K, Tong M, Lin D. Toxicity of TiO2nanoparticles to Escherichia coli: effects of particle size, Crystal Phase and Water Chemistry. PLoS One. 2014;9(10):e110247.

49. Pagnout C, Jomini S, Dadhwal M, Caillet C, Thomas F, Bauda P. Role of electrostatic interactions in the toxicity of titanium dioxide nanoparticles toward Escherichia Coli. Colloids Surfaces B Biointerfaces. 2012:92:315-21.

50. Singh V, Beltran IJC, Ribot JC, Nagpal P. Photocatalysis deconstructed: Design of a new Selective Catalyst for artificial photosynthesis. Nano Lett. 2014;14(2):597-603.

51. Alivov Y, Singh V, Ding Y, Cerkovnik LJ, Nagpal P. Doping of wide-Bandgap titanium-dioxide nanotubes: optical, Electronic and Magnetic Properties. Nanoscale. 2014:6(18):10839-49.

52. Alivov $Y$, Funke $H H$, Singh $V$, Nagpal P. Air-pressure tunable depletion width, rectification behavior, and charge conduction in oxide nanotubes. ACS Appl Mater Interfaces. 2015;7(4):2153-9.

53. Xiong LB, Li JL, Yang B, Yu Y. Ti 3+ in the Surface of Titanium Dioxide: Generation, Properties and Photocatalytic Application. J Nanomaterials. 2012;9.

54. Lewinski N, Colvin V, Drezek R. Cytotoxicity of nanoparticles. Small. 2008;4(1): 26-49.

55. Hardman R. A Toxicologic Review of Quantum Dots: Toxicity Depends on Physicochemical and Environmental Factors. Environmental Health Perspectives. 2006:165-72.

56. Andorko J, Jewell CM. Designing biomaterials with Immunomodulatory properties for tissue engineering and regenerative medicine. Med: Bioeng Transl; 2017.

57. Lewis JS, Roy K, Keselowsky BG. Materials That Harness and Modulate the Immune System. MRS Bull. 2014;39(1):25-34.

58. Li C-B, Li Z-J, Yu S, Wang G-X, Wang F, Meng Q-Y, Chen B, Feng K, Tung C$\mathrm{H}$, Wu L-Z. Interface-directed assembly of a simple precursor of [FeFe]H2ase mimics on CdSe QDs for photosynthetic hydrogen evolution in water. Energy Environ Sci. 2013;6(9):2597-602.

59. Fernández TD, Pearson JR, Leal MP, Torres MJ, Blanca M, Mayorga C, Le Guével $X$ Intracellular accumulation and immunological properties of fluorescent gold Nanoclusters in human dendritic cells. Biomaterials. 2015:43:1-12.

60. Da Silva CA, Chalouni C, Williams A, Hartl D, Lee CG, Elias JA. Chitin is a sizedependent regulator of macrophage TNF and IL-10 production. J Immunol. 2009;182(6):3573-82.

61. Kumar S, Anselmo AC, Banerjee A, Zakrewsky M, Mitragotri S. Shape and size-dependent immune response to antigen-carrying nanoparticles. J Control Release. 2015;220:141-8.

62. Padmore T, Stark C, Turkevich LA, Champion JA. Quantitative analysis of the role of Fiber length on phagocytosis and inflammatory response by alveolar macrophages. Biochim. Biophys. Acta - Gen. Subj. 2017;1861(2):58-67.

63. Moyano DF, Goldsmith M, Solfiell DJ, Landesman-Milo D, Miranda OR, Peer D, Rotello VM. Nanoparticle hydrophobicity dictates immune response. J Am Chem Soc. 2012;134(9):3965-7.

64. Bartneck M, Keul HA, Singh S, Czaja K, Bornemann J, Bockstaller M, Moeller M, Zwadlo-Klarwasser G, Groll J. Rapid uptake of gold Nanorods by primary human blood phagocytes and Immunomodulatory effects of surface chemistry. ACS Nano. 2010;4(6):3073-86.

65. Wen Y, Waltman A, Han H, Collier JH. Switching the immunogenicity of peptide assemblies using surface properties. ACS Nano. 2016;10(10): 9274-86.

66. Zhang L, Cao Z, Bai T, Carr L, Ella-Menye JR, Irvin C, Ratner BD, Jiang S. Zwitterionic hydrogels implanted in mice resist the foreign-body reaction. Nat Biotechnol. 2013;31(6):553-6.

67. Christo SN, Bachhuka A, Diener KR, Mierczynska A, Hayball JD, Vasilev K. The role of surface Nanotopography and chemistry on primary neutrophil and macrophage cellular responses. Adv Healthc Mater. 2016;5(8):956-65.

68. Bracho-Sanchez E, Xia CQ, Clare-Salzler MJ, Keselowsky BG. Micro and Nano Material Carriers for Immunomodulation. AM J Transplant. 2016; 16(12):3362-70. 
69. Banerjee A, Qi J, Gogoi R, Wong J, Mitragotri S. Role of Nanoparticle Size, Shape and Surface Chemistry in Oral Drug Delivery. J. Control. Release. 2016.

70. Seong SY, Matzinger P. Hydrophobicity: An Ancient Damage-Associated Molecular Pattern That Initiates Innate Immune Responses. Nature Rev Immunol. 2004:469-78.

71. Li WA, Lu BY, Gu L, Choi Y, Kim J, Mooney DJ. The effect of surface modification of Mesoporous silica micro-rod scaffold on immune cell activation and infiltration. Biomaterials. 2016;83:249-56.

72. Gallorini S, Berti F, Parente P, Baronio R, Aprea S, D'Oro U, Pizza M, Telford $J$, Wack A. Introduction of Zwitterionic motifs into bacterial polysaccharides generates TLR2 agonists able to activate APCs. J Immunol. 2007;179(12): 8208-15.

73. Getts DR, Terry RL, Getts MT, Deffrasnes C, Müller M, Vreden C, Ashhurst TM, Chami B, McCarthy D, Wu H, et al. Therapeutic inflammatory monocyte modulation using immune-modifying microparticles. Sci Transl Med. 2014; 10:9274-86

74. Butler KS, Peeler DJ, Casey BJ, Dair BJ, Elespuru RK. Silver nanoparticles: correlating nanoparticle size and cellular uptake with Genotoxicity. Mutagenesis. 2015;30:577-91.

75. Shang L, Nienhaus K, Nienhaus GU. Engineered Nanoparticles Interacting with Cells: Size Matters. Journal of Nanobiotechnology. 2014:12:5.

76. Goodman SM, Siu A, Singh V, Nagpal P. Long-range energy transfer in selfassembled quantum dot-DNA cascades. Nanoscale. 2015:7(44):18435-40.

77. Noh H, Goodman SM, Mohan P, Goodwin AP, Nagpal P, Cha JN. Direct conjugation of DNA to quantum dots for scalable assembly of photoactive thin films. RSC Adv. 2014;4(16):8064-71

78. Goodman SM, Singh V, Ribot JC, Chatterjee A, Nagpal P. Multiple energy Exciton shelves in quantum-dot - DNA Nanobioelectronics. J Phys Chem Lett. 2014;5:3909-13.

79. Goodman SM, Noh H, Singh V, Cha JN, Nagpal P. Charge Transport through Exciton Shelves in Cadmium Chalcogenide Quantum Dot-DNA NanoBioelectronic Thin Films. Appl. Phys. Lett. 2015;106(8):083109.

80. Chan WCW, Nie S. Quantum Dot Bioconjugates for Ultrasensitive Nonisotopic Detection. Science (80-. ). 1998;281:2016-8.

81. Farokhzad OC, Karp JM, Langer R. Nanoparticle-aptamer bioconjugates for Cancer targeting. Expert Opin Drug Deliv. 2006;3(3):311-24.

82. Gáspár S. Detection of superoxide and hydrogen peroxide from living cells using electrochemical sensors. Diagnostics, Prevention, and Therapy: Oxidative Stress; 2011.

83. Lu, Q:; Yu, Y.; Ma, Q.; Chen, B.; Zhang, H. 2D Transition-MetalDichalcogenide-Nanosheet-Based Composites for Photocatalytic and Electrocatalytic Hydrogen Evolution Reactions. 2015, No. March 2018.

84. Tamirat AG, Rick J, Dubale AA, Su W, Hwang B. Using Hematite for Photocatalytic Water Splitting: A Review of Current Developments and Challenges. Nanoscale Horizons. 2016;1(4):243-67.

85. Derfus AM, Chan WCW, Bhatia SN. Probing the cytotoxicity of semiconductor quantum dots. Nano Lett. 2004;4(1):11-8.

86. Liu W, Zhang S, Wang L, Qu C, Zhang C, Hong L, Yuan L, Huang Z, Wang Z, Liu S, et al. CdSe Quantum Dot (QD)-Induced Morphological and Functional Impairments to Liver in Mice. PLoS One. 2011;6(9):e24406.

87. Chang E, Thekkek N, Yu WW, Colvin VL, Drezek R. Evaluation of quantum dot cytotoxicity based on intracellular uptake. Small. 2006;2(12):1412-7.

88. Haque MM, Im HY, Seo JE, Hasan M, Woo K, Kwon OS. Acute toxicity and tissue distribution of CdSe/CdS-MPA quantum dots after repeated Intraperitoneal injection to mice. J Appl Toxicol. 2013;33(9): 940-50.

89. Male KB, Lachance B, Hrapovic S, Sunahara G, Luong JHT. Assessment of cytotoxicity of quantum dots and gold nanoparticles using cell-based impedance spectroscopy. Anal Chem. 2008;80(14):5487-93.

90. Law WC, Yong KT, Roy I, Ding H, Hu R, Zhao W, Prasad PN. Aqueous-phase synthesis of highly luminescent CdTe/ZnTe Core/shell quantum dots optimized for targeted bioimaging. Small. 2009;5(11):1302-10.

91. Cho SJ, Maysinger D, Jain M, Röder B, Hackbarth S, Winnik FM. Long-term exposure to CdTe quantum dots causes functional impairments in live cells. Langmuir. 2007;23(4):1974-80.

92. Zhang $T, H u$ Y, Tang $M$, Kong $L$, Ying J, Wu T, Xue $Y, P u$ Y. Liver toxicity of cadmium telluride quantum dots (CdTe QDs) due to oxidative stress in vitro and in vivo. Int J Mol Sci. 2015;16(10):23279-99.

93. Lovrić J, Bazzi HS, Cuie Y, Fortin GRA, Winnik FM, Maysinger D. Differences in subcellular distribution and toxicity of Green and red emitting CdTe quantum dots. J Mol Med. 2005;83(5):377-85.
94. Yong KT, Roy I, Law WC, Hu R. Synthesis of CRGD-peptide conjugated nearinfrared CdTe/ZnSe Core-Shell quantum dots for in vivo Cancer targeting and imaging. Chem Commun. 2010;46(38):7136-8.

95. Yong KT, Roy I, Hu R, Ding H, Cai H, Zhu J, Zhang X, Bergey EJ, Prasad PN. Synthesis of ternary CulnS2/ZnS quantum dot bioconjugates and their applications for targeted Cancer bioimaging. Integr Biol. 2010;2(23):121-9.

96. Pons, T.; Pic, E.; Lequeux, N.; Cassette, E.; Bezdetnaya, L.; Dubertret, B. Cadmium-Free cuins2/ZnS Quantum Dots for Sentinel Lymph Node Imaging with Reduced Toxicity. 2010, XXX (XX), 4-11.

97. Ayupova D, Dobhal G, Laufersky G, Nann T, Goreham R. An in vitro investigation of cytotoxic effects of InP/Zns quantum dots with different surface chemistries. Nanomaterials. 2019;9(2):135.

98. Zhang L, Yang XQ, An J, Zhao SD, Zhao TY, Tan F, Cao YC, Zhao YD. In vivo tumor active Cancer targeting and CT-fluorescence dual-modal imaging with Nanoprobe based on gold Nanorods and InP/ZnS quantum dots. J Mater Chem B. 2018;6(17):2574-83.

99. Yaghini E, Turner H, Pilling A, Naasani I, MacRobert AJ. In vivo biodistribution and toxicology studies of cadmium-free indium-based quantum dot nanoparticles in a rat model. Nanomedicine Nanotechnology, Biol Med. 2018;14(8):2644-55.

100. Karlsson HL, Cronholm P, Gustafsson J, Mo L. Copper oxide nanoparticles are highly toxic: a comparison between metal oxide nanoparticles and carbon nanotubes - chemical research in toxicology (ACS publications). Chem Res Toxicol. 2008:1726-32.

101. Cho Y, Ivansevic A. In vitro assessment of the biocompatibility of chemically modified GaAs surfaces. J Med Dent Sci. 2006;2:51-60.

102. Webb DR, Sipes IG, Carter DE. In vitro solubility and in vivo toxicity of gallium arsenide. Toxicol Appl Pharmacol. 1984;76(1):96-104.

103. Manzoor K, Johny S, Thomas D, Setua S, Menon D, Nair S. Bio-Conjugated Luminescent Quantum Dots of Doped ZnS: A Cyto-Friendly System for Targeted Cancer Imaging. Nanotechnology. 2009;20(6):065102.

104. Yang Y, Lan J, Xu Z, Chen T, Zhao T, Cheng T, Shen J, Lv S, Zhang H. Toxicity and biodistribution of aqueous synthesized $\mathrm{ZnS}$ and $\mathrm{ZnO}$ quantum dots in mice. Nanotoxicology. 2014;8(1):107-16.

105. Wang $T$, Hsieh H, Hsieh Y, Chiang C, Sun Y, Wang C. The in vivo biodistribution and fate of CdSe quantum dots in the murine model: a lase ablation inductively coupled plasma mass spectrometry study. Anal Bioanal Chem. 2012:404(10):3025-36.

106. Robe A, Pic E, Lassalle HP, Bezdetnaya L, Guillemin F, Marchal F. Quantum dots in axillary lymph node mapping: biodistribution study in healthy mice. BMC Cancer. 2008:8:1-9.

107. Nagy A, Steinbrück A, Gao J, Doggett N, Hollingsworth JA, lyer R. Comprehensive analysis of the effects of CdSe quantum dot size, surface charge, and functionalization on primary human lung cells. ACS Nano. 2012; 6(6):4748-62.

108. Xiao K, Liu Q, Li H, Xia Q, Liu Y. Role of surface charge in determining the biological effects of CdSe/ZnS quantum dots. Int J Nanomedicine. 2015; 10:7073

109. Hirn S, Semmler-behnke M, Schleh C, Wenk A, Schäffler M, Takenaka S, Möller W, Schmid G, Kreyling WG. Particle size-dependent and surface charge-dependent biodistribution of gold nanoparticles after intravenous administration. Eur Journal Biopharm. 2012;77(3):407-16.

Ready to submit your research? Choose BMC and benefit from:

- fast, convenient online submission

- thorough peer review by experienced researchers in your field

- rapid publication on acceptance

- support for research data, including large and complex data types

- gold Open Access which fosters wider collaboration and increased citations

- maximum visibility for your research: over $100 \mathrm{M}$ website views per year

At $\mathrm{BMC}$, research is always in progress.

Learn more biomedcentral.com/submissions 